\title{
PENGEMBANGAN GAME SASTRA (GASAS) UNTUK PEMBELAJARAN KARYA SASTRA DARI BERBAGAI ANGKATAN BAGI SISWA SMP
}

\author{
Eri Syafitri Hasudungan ${ }^{1)}$, Wika Soviana Devi ${ }^{2)}$ \\ ${ }^{1), 2)}$ Pendidikan Bahasa dan Sastra Indonesia, Fakultas Ilmu Pendidikan, \\ Universitas Muhammadiyah Jakarta, Jl KH Ahmad Dahlan, Cirendeu, Ciputat, Jakarta Selatan \\ $\frac{{ }^{1} \text { Erisyafitri96@gmail.com }}{{ }^{2} \text { wikasoviana@umj.ac.id }}$
}

\section{ABSTRAK}

Penelitian ini dilatarbelakangi karena ketertarikan akan keunikan penggunaan bahasa (diksi dan gaya kalimat) dalam novel Hafalan Shalat Delisa karya Tere Liye. Penelitian ini bertujuan untuk (1) mendeskripsikan diksi yang terdapat dalam novel Hafalan Shalat Delisa karya Tere Liye;dan (2) mendeskripsikan gaya kalimat yang terdapat dalam novel Hafalan Shalat Delisa karya Tere Liye. Jenis penelitian ini adalah penelitian deskriptif. Subjek penelitian ini adalah novel Hafalan Shalat Delisa karya Tere Liye, sedangkan objek penelitian ini adalah diksi dan gaya kalimat dalam novel Hafalan Shalat Delisa karya Tere Liye sebagai alternatif bahan ajar sastra di SMA. Metode pengumpulan data dilakukan dengan menggunakan teknik kepustakaan, simak/sadap, dan catat. Instrumen penelitian yang digunakan berupa teks novel Hafalan Shalat Delisa karya Tere Liye. Hasil penelitian ini sebagai berikut. (1) Diksi yang paling dominan digunakan dalam novel Hafalan Shalat Delisa karya Tere Liye adalah kata-kata asing yang diasumsikan sebagai gambaran kemampuan pengarang dalam penguasaan bahasa lain. (2) Gaya kalimat yang paling dominan digunakan dalam novel Hafalan Shalat Delisa karya Tere Liye adalah kalimat dengan sarana retorika, hal ini menunjukkan pengarang memanfaatkan sarana retorika agar pesan yang ingin disampaikan lewat cerita dapat diterima dan diinterpretasi oleh banyak dari berbagai sudut pandang.

Kata kunci: diksi, gaya kalimat, Hafalan Shalat Delisa, Tere Liye

\section{PENDAHULUAN}

Bahasa Indonesia adalah bahasa yang berasal dari bahasa Melayu. Saat ini masyarakat Indonesia tidak menggunakan bahasa Melayu melainkan bahasa Indonesia. Pembelajaran kesusastraan Indonesia merupakan bagian dari kajian ilmu sastra. Dalam kajiannya sastra memiliki beberapa bidang kajian yaitu teori sastra, sejarah sastra, dan kritik sastra. Sastra Indonesia adalah sebuah istilah yang mencakup berbagai karya sastra yang berada di Indonesia. Jenis karya sastra terbagi tiga yakni, puisi, prosa, dan drama. Sedangkan 
Eri Syafitri Hasudungan ${ }^{1)}$,, Wika Soviana Devi ${ }^{2)}$ : Pengembangan Game Sastra (Gasas) untuk Pembelajaran Karya Sastra dari Berbagai Angkatan bagi Siswa SMP

Website : https://jurnal.umj.ac.id/index.php/penaliterasiEmail : penaliterasi@umj.ac.id

karya sastra memberikan pengetahuan tentang berbagai hal yang belum diketahui oleh pembaca. Sebuah karya sastra tercipta berdasarkan imajinasi dan proses kreatif terhadap realitas kehidupan seorang pengarang. Karya sastra merupakan kehidupan buatan atau rekaan sastrawan. Kehidupan di dalam karya sastra beragam dengan sikap penulisnya dan keyakinannya.

Sejarah sastra merupakan bagian ilmu sastra yang memperlihatkan perkembangan karya sastra, tokoh-tokohnya dan ciri-ciri dari masing-masing perkembangan tersebut. Dalam sejarah sastra Indonesia dikenal dengan istilah angkatan sastrawan atau periodisasi sastra. Angkatan atau periodisasi sastra adalah kelompok sastrawan dalam suatu masa tertentu berdasarkan ciri khas karya yang dihasilkan pada masa itu. Periodisasi sastra bisa juga dibilang penggolongan sastra berdasarkan pembabakan waktu dari awal kemunculan sampai dengan perkembangannya. Angkatan sastrawan atau periodisasi sastra bisa diketahui dari angkatan pujangga lama, balai pustaka, pujangga baru, angkatan 1945, angkatan 1950, angkatan 1966, angkatan 1970, angkatan 1980, angkatan 1990 atau era reformasi, dan angkatan 2000 sampai sekarang.

Salah satu KD yang dipelajari yaitu "Menelaah Unsur Buku Fiksi dan Nonfiksi yang Dibaca". Menurut KD yang ada peneliti membuat penelitian tentang pengembangan game sastra (gasas) untuk pembelajaran karya sastra dari berbagai angkatan bagi siswa SMP. Sekolah yang peneliti observasi belum

menggunakan media pembelajaran yang memadai tentang karya sastra, padahal KD sastra ada di kelas 7-9. Game yang dibuat merupakan game edukasi menggunakan aplikasi unity 3D. Game ini membantu menarik minat belajar siswa untuk membaca tentang karya sastra dari berbagai angkatan.

Sebagai data awal peneliti mengunjungi dua SMP untuk mengobservasi. Observasi dilakukan September 2018, data yang peneliti dapat dari dua SMP tersebut sama. Kedua sekolah itu memiliki ruang komputer untuk penelitian game sastra yang peneliti buat. Oleh karena itu, peneliti mengambil dua sekolah yang sarana prasananya memiliki ruang komputer. Sekolah pertama bernama SMP Keluarga Widuri dan sekolah yang kedua bernama SMP Al-Hidayah sekolah tersebut terletak di daerah Lebak Bulus kota Jakarta Selatan. SMP Widuri memiliki fasilitas ruang belajar ber-AC, laboratorium komputer, mushola, aula, perpustakaan dan lain-lain. Sama seperti sekolah yang pertama SMP Al-Hidayah juga memiliki fasilitas laboratorium komputer, laboratorium sains, mushola, dan perpustakaan. Peneliti akan melihat game yang dibuat apakah dapat berpengaruh untuk pembelajaran bahasa Indonesia di SMP tersebut atau tidak.

Peneliti membuat game sastra untuk memberikan rasa senang dalam belajar bahasa Indonesia khususnya dalam materi sastra. Game untuk siswa SMP sangat banyak saat ini, tetapi bukan game edukasi melainkan game yang hanya membuat siswa merasa senang, jarang ada unsur edukasi atau pembelajarannya. Game edukasi atau game pembelajaran untuk siswa SMP belum sebanyak game untuk anak usia dini atau anak SD. Game edukasi yang sudah ada dan bisa dimainkan oleh siswa SMP hanya membahas tentang semua mata pelajaran di sekolah dan tidak ada unsur permainan di dalamnya. Oleh karena itu, peneliti 
Eri Syafitri Hasudungan ${ }^{1)}$,, Wika Soviana Devi ${ }^{2)}$ : Pengembangan Game Sastra (Gasas) untuk Pembelajaran Karya Sastra dari Berbagai Angkatan bagi Siswa SMP

Website : https://jurnal.umj.ac.id/index.php/penaliterasiEmail : penaliterasi@umj.ac.id

mengembangkan game edukasi yang bernama game sastra dengan materi pembelajaran karya sastra dari berbagai angkatan bagi siswa SMP.

Siswa SMP masih suka bermain game daring atau luring. Game yang peneliti buat merupakan game edukasi yang mudah dimainkan oleh anak SMP. Dalam game ini siswa akan diberi pilihan menu belajar dan permainan. Ada pembelajaran tentang sastrawan beserta karyanya dan permainan tebak sastrawan serta game memori. Setelah selesai memilih menu, siswa bisa belajar mengenal sastrawan dengan menekan gambarnya dan membaca penjelasannya.

Berdasarkan hasil di atas dapat disimpulkan betapa pentingnya menambah media pembelajaran untuk karya sastra dari berbagai angkatan bagi siswa SMP. Dengan menggunakan media game sastra (gasas) diharapkan siswa dapat lebih mengenal karya sastra dan sastrawan Indonesia. Peneliti melakukan penelitian dengan judul pengembangan game sastra (gasas) untuk pembelajaran karya sastra dari berbagai angkatan bagi siswa SMP.

Secara umum tujuan penelitian ini dimaksudkan untuk mengetahui peran media pembelajran game sastra (gasas) untuk pembelajaran karya sastra dari berbagai angkatan bagi siswa SMP dan untuk menarik minat anak dalam belajar. Mengembangkan kreativitas anak, karena dalam game sastra memiliki unsur tantangan, ketepatan, daya berpikir, dan etika. Secara khusus penelitian ini bertujuan untuk mengetahui keterbacaan penggunaan game sastra dalam mendukung pembelajaran karya sastra dari berbagai angkatan bagi siswa SMP dan mengetahui proses pembuatan media game sastra yang telah dikembangkan bagi siswa SMP.

\section{METODE PENELITIAN}

Metode yang digunakan penelitian ini adalah metode pengembangan atau Research and Development. Metode pengembangan adalah penelitian yang digunakan untuk menghasilkan produk tertentu, dan menguji keefektifan produk tersebut (Sugiyono: 297). Menurut Sukmadinata dalam Wynarti (2018: 65) penelitan pengembangan merupakan pendekatan penelitian untuk menghasilkan suatu produk baru atau menyempurnakan produk yang telah ada. Penelitian pengembangan atau Research and Development (R\&D) atau sering disebut penelitian pengembangan adalah strategi atau metode penelitian yang cukup ampuh untuk memperbaiki praktik pembelajaran. Berdasarkan pendapat di atas dapat disimpulkan bahwa penelitian pengembangan adalah penelitian untuk menghasilkan suatu produk baru atau mengembangkan produk yang sudah ada.

Media yang dikembangkan penelitian ini berupa produk media game untuk pembelajaran karya sastra dari berbagai angkatan bagi siswa SMP. Langkah-langkah penelitian dan pengembangan ini menggunakan langkah-langkah yang dikemukakan Borg and Gall dalam Emzir (2015: 271) dengan 10 tahap, yaitu 1) penelitian dan pengumpulan informasi, 2) perencanaan, 3) pengembangan bentuk awal produk, 4) uji lapangan awal, 5) revisi produk, 6) uji lapangan utama, 7) revisi produk oprasional, 8) uji lapangan oprasional, 9) revisi produk akhir, dan 10) diseminasi dan implementasi.

Peneliti membatasi tahapan penelitian dikarenakan sesuai kebutuhan yang akan 
Eri Syafitri Hasudungan ${ }^{1)}$, Wika Soviana Devi ${ }^{2)}$ : Pengembangan Game Sastra (Gasas) untuk Pembelajaran Karya Sastra dari Berbagai Angkatan bagi Siswa SMP

Website : https://jurnal.umj.ac.id/index.php/penaliterasiEmail : penaliterasi@umj.ac.id

dicapai, keterbatasan peneliti pada waktu peneltian dan biaya. Hal ini juga diperkuat oleh teori Borg and Gall (2003: 572) jika anda berencana melakukan proyek $R \& D$ untuk penelitian atau disertasi, anda harus mengingat ini. Cara terbaik untuk melakukan proyek skala kecil yang melibatkan sejumlah rancangan. Selain itu, jika anda tidak memiliki dana yang besar, anda harus menghindari media instruksional yang mahal seperti film. Cara lain untuk membatasi pengembangan hanya pada beberapa langkah saja. Dengan bagan sebagai berikut.

\section{Penelitian dan Pengumpulan Informasi}

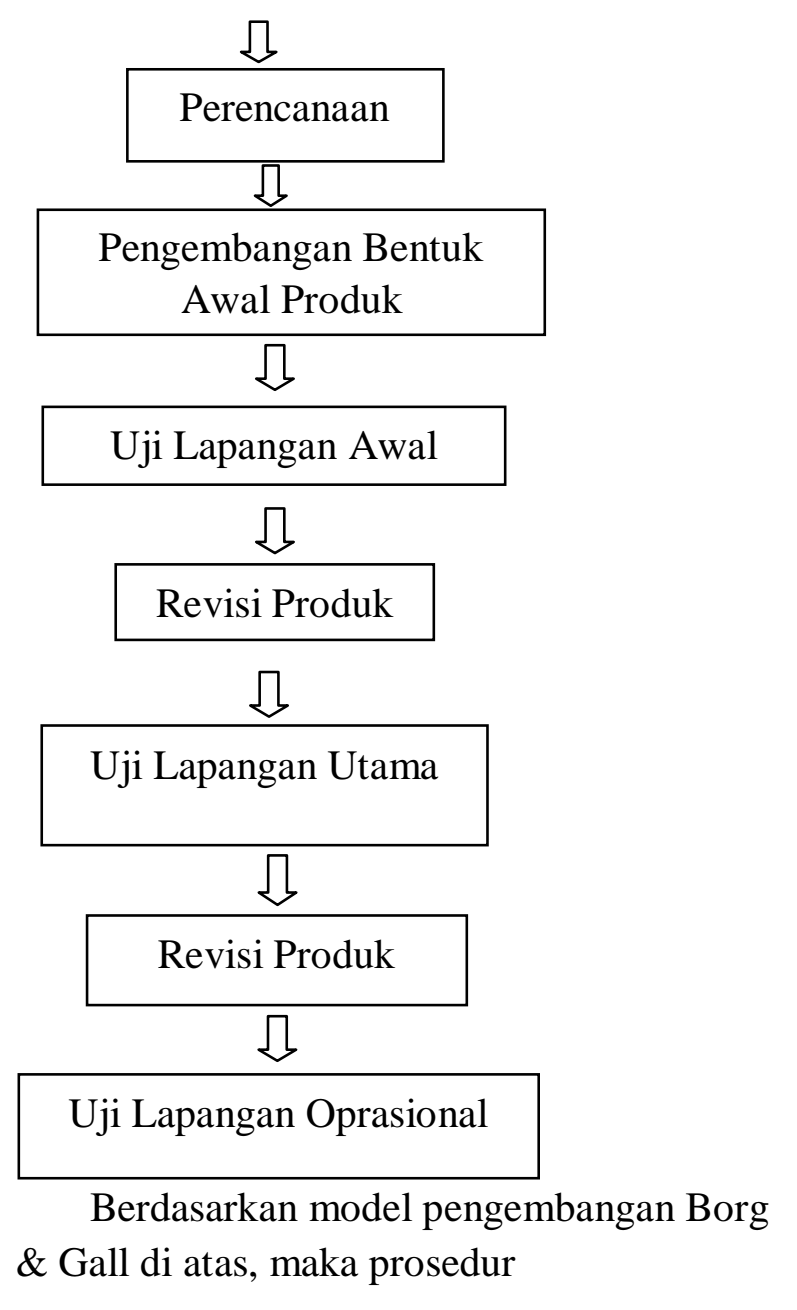

pengembangan dapat digambarkan dalam tahapan-tahapan berikut ini.

1. Penelitian dan Pengumpulan Informasi Tahap pertama dan model pengembangan Borg \& Gall adalah penelitian dan pengumpulan informasi awal. Tahap ini bertujuan untuk memperoleh informasi guna mendukung penelitian pengembangan. Tahapan ini dapat berupa studi lapangan dan juga studi literatur.

2. Perencanaan

Tahap perencanaan merupakan tahapan kedua dalam prosedur pengembangan ini. Tahapan ini bertujuan untuk mendesain bagaimana produk yang akan dihasilkan. Produk yang akan dikembangkan dalam penelitian pengembangan ini adalah game sastra. Game sastra yang peneliti buat berdasarkan kompetensi dasar yang ada di kurikulum 2013 yaitu menelaah unsur buku fiksi dan nonfiksi yang dibaca.

3. Pengembangan Produk Awal

Tahapan ketiga ini bertujuan untuk mengembangkan produk awal. Semua yang sudah direncanakan pada tahap perencanaan dikerjakan pada tahapan ini. Pengumpukan materi dalam game sastra dilakukan dalam tahap ini. Tahapan ini juga menentukan bagaimana struktur game sastra yang akan dicapai. Pengembangan game sastra yang dihasilkan pada tahap sebelumnya akan diuji cobakan. Tahap uji validasi produk dilakukan untuk mengevaluasi dan memvalidasi yang dihasilkan. Validasi dan evaluasi akan dilakukan oleh ahli materi dan ahli media

4. Uji Lapangan Awal 
Eri Syafitri Hasudungan ${ }^{1}$,, Wika Soviana Devi ${ }^{2)}$ : Pengembangan Game Sastra (Gasas) untuk Pembelajaran Karya Sastra dari Berbagai Angkatan bagi Siswa SMP

Website : https://jurnal.umj.ac.id/index.php/penaliterasiEmail : penaliterasi@umj.ac.id

Uji coba lapangan awal ini dilakukan dengan uji coba pada kelompok kecil. Seperti telah dikemukakan, kalau dalam bidang teknik, desain produk yang telah dibuat tidak bisa langsung diuji coba, tetapi harus dibuat terlebih dahulu menjadi barang, dan barang tersebut yang diuji coba. Pengujian ini dilakukan dengan tujuan mendapatkan informasi penggunaan pengembangan game sastra dalam pembelajaran karya sastra dari berbagai angkatan bagi siswa SMP.

5. Revisi Produk

Revisi produk dilakukan berdasarkan peniliain dan catatan khusus pada tahap uji coba. Kesalahan dan kekurangan produk yang dihasilkan akan diperbaiki berdasarkan catatan dari tim validasi, sehingga didapatkan bahan ajar yang telah teruji secara internal dan siap dilakukan untuk uji coba terbatas.

6. Uji Lapangan Utama

Tahap uji coba utama dilakukan setelah melalui tahap revisi produk. Game sastra telah direvisi akan diujicobakan kembali. Subjek uji coba tutama dalam penelitian ini adalah siswa SMP Keluarga Widuri dan SMP Al-Hidayah. Uji coba utama tidak jauh berbeda dengan uji coba awal. Uji coba utama bertujuan untuk mengumpulkan penilaian dan komentar dari subjek uji coba awal. Instrumen yang digunakan dalam pengumpulan nilai berupa angket, observasi dan wawancara.

7. Revisi Produk

Revisi produk perlu dilaksanakan karena dalam pengujian masih terdapat kekurangan atau kelemahan yang diketahui dari hasil pengamatan, angket dan wawancara yang sudah dinilai oleh ahli media dan ahli materi. Perlunya direvisi agar kreativitas siswa dalam belajar dapat meningkat.

8. Uji Lapangan Oprasional

Uji lapangan oprasional setelah pengujian terhadap produk berhasil, dan mungkin ada revisi yang tidak terlalu penting, maka selanjunya produk yang berupa media baru tersebut diterapkan.

Dalam hal ini ahli media yang dipilih oleh peneliti adalah bapak Hendra, St., Mt. selaku dosen teknik Informatika di Fakultas Teknik Universitas Muhammadiyah Jakarta dan ibu Riza Syamsinar, St., Mt. selaku dosen teknik Elektro di Fakultas Teknik Universitas Muhammadiyah Jakarta. Ahli materi dalam penelitian ini adalah sastrawan angkatan 66 yaitu Prof. Dr. Sapardi Djoko Damono selaku guru besar di Universitas Indonesia dan bapak Abidin Ahmad M. Pd selaku pengawas sekolah dan guru bahasa Indonesia di beberapa SMP daerah Jakarta Selatan.

Metode penelitian ini menggunakan jenis desain posttest-only control design. Dalam desain ini, Sugiyono (2016:76) menyatakan bahwa terdapat dua kelompok yang masing-masing dipilih secara random. Subyek dalam penelitian ini adalah siswa kelas VIII SMP Keluarga Widuri dan siswa SMP kelas VIII SMP Al-Hidayah. Pengambilan sample dalam penelitian ini menggunakan kelas VIII-1 dan VIII-2 SMP Keluarga Widuri begitipun sebaliknya di SMP Al-Hidayah. Kelompok diberi perlakuan (kelas eksperimen) dan kelompok yang tidak diberi perlakuan (kelas kontrol). Hasil yang diperoleh akan dijadikan ujicoba untuk melihat respon siswa di kelas eksperimen menggunakan media game sastra, sedangkan di kelas kontrol tidak menggunakan media game sastra. Penilaian menggunakan skala rating scale dengan 4 alternatif jawaban. 4 = sangat baik, $3=$ 
Eri Syafitri Hasudungan ${ }^{1)}$,, Wika Soviana Devi ${ }^{2)}$ : Pengembangan Game Sastra (Gasas) untuk Pembelajaran Karya Sastra dari Berbagai Angkatan bagi Siswa SMP

Website : https://jurnal.umj.ac.id/index.php/penaliterasiEmail : penaliterasi@umj.ac.id

cukup baik, 2 = kurang baik dan $1=$ tidak baik.

\section{HASIL DAN PEMBAHASAN}

Penelitian pengembangan ini peneliti buat untuk menambahkan bahan ajar khususnya untuk pembelajaran bahasa Indonesia materi pembelajaran sastra dari berbagai angkatan dengan $\mathrm{KD}$ menelaah unsur buku fiksi dan nonfiksi yang dibaca. Peneliti mengembangkan bahan ajar berupa game sastra untuk memberikan media baru kepada murid di sekolah. Game yang peneliti buat sama seperti game marbel (mari belajar). Peneliti kemudian mengembangkan game marbel menjadi game sastra dengan materi pembelajaran sastra dari berbagai angkatan. Hasil Pengujian tahap I, peneliti melihat dari saran, komentar dan hasil validasi ahli media dan ahli materi. Saran ahli media untuk meningkatkan media game yang dikembangkan, ahli media memberikan masukan mengenai apa saja yang harus diperbaiki, yaitu: 1) awal masuk tambahkan corak agar tidak terlihat polos. Tombol exit dan tombol kembali diberi tanda seperti tanda panah lalu buat agak besar agar kelihatan tulisannya, warna tulisan yang cerah. 2) Kalimat "tebak sastrawannya" dan "game memori" diberi frame dan warnanya diganti dengan yang cerah. Dalam game memori tulisan "kembali", "level selanjutnya", "level satu", "skor" dan "waktu" diperbesar tulisannya dan ditambahin corak yang menarik agar tidak terlalu polos. 3) dalam game tebak sastrawan ada "kata pertanyaan 1" ditambahin saja menjadi "pertanyaan 1-20", di bawah game "tebak sastrawan" dan "game memori" masih terlihat kosong tambahin tulisan

"Bermain Bukan Hanya Untuk BersenangSenang, Tetapi Bisa Juga Untuk Menambah Ilmu Pengetahuan". 4) gambar diperbagus dan ditambahkan resolusinya. Tulisan exit bila diklik seharusnya bukan kembli ke menu utama tetapi kembali ke menu permainan.

Saran ahli materi untuk mengetahui kelayakan materi yang peneliti ujikan kepada murid di sekolah. 1) Materi sebaiknya tidak berpedoman dari internet melainkan dari buku atau novel sastrawan. 2) Tuntaskan materi ini jangan samapi hanya dijadikan skripsi lanjutkan dan aplikasikan sebagai pembelajaran di sekolah akan lebih baik. 3) Sumber gambar boleh dari internet tetapi tidak diperbolehkan dari wikipedia.

Hasil Pengujian tahap II dilakukan karena pada saat peneliti melakukan wawancara banyak saran dan komentar dari ahli media sedangkan ahli materi sudah memberikan hasil yang sangat baik. Hasil pengujian II tidak ada revisi dari ahli media atau ahli materi karena perbaikan hasil pengujian I sudah dikerjakan dengan baik dan sesuai dengan apa yang ahli materi dan ahli media katakan sebelumnya.

Validasi ahli media tahap II menunjukan hasil dengan jumlah nilai sebesar 71 kategori "sangat baik". Begitupun dengan validasi ahli materi tahap II, mendapatkan skor baik yaitu 73 . Berdasarkan hasil validasi diatas maka dapat disimpulkan bahwa media game sastra layak dijadikan untuk bahan ajar di sekolah. Hal itu bisa dilihat dari table berikut: 
Eri Syafitri Hasudungan ${ }^{1)}$, Wika Soviana Devi ${ }^{2)}$ : Pengembangan Game Sastra (Gasas) untuk Pembelajaran Karya Sastra dari Berbagai Angkatan bagi Siswa SMP Website : https://jurnal.umj.ac.id/index.php/penaliterasiEmail : penaliterasi@umj.ac.id

\section{1 \\ Hasil Analisis Kelayakan Bahan Ajar Oleh Ahli Media Dan Materi}

Hasil perhitungan pengujian satu di SMP Keluarga Widuri dengan rumus sebagai berikut:

$\mathbf{S}=\mathbf{R} \frac{\mathbf{W}}{\mathbf{n}-\mathbf{1}}$

Keterangan:

$\mathrm{S} \quad=$ Skor

$\mathrm{R}$ (right) = Jumlah Jawaban Betul

$\mathrm{W}$ (wrong)=Jumlah Jawaban Yang Salah

$\mathrm{n} \quad=$ Jumlah Alternatif Jawaban (opsi)

$S=19 \frac{1}{4-1}=18$

Hasil perhitungan pengujian dua di SMP Al-Hidayah dengan rumus sebagai berikut:

$$
\mathbf{S}=\mathbf{R} \frac{\mathbf{W}}{\mathbf{n}-\mathbf{1}}
$$

Keterangan:

$\mathrm{S}=$ Skor

$\mathrm{R}($ right $)=$ Jumlah Jawaban Betul

$\mathrm{W}($ wrong $)=$ Jumlah Jawaban Yang Salah

$\mathrm{n} \quad=$ Jumlah Alternatif Jawaban (opsi)

$S=20 \frac{1}{4-1}=19$

Hasil keseluruhan secara umum baik dari hasil validasi ahli media dan validasi ahli materi terhadap, pengembangan game sastra untuk pembelajaran karya sastra dari berbagai angkatan bagi siswa SMP

\begin{tabular}{|c|l|c|c|c|}
\hline No & \multicolumn{1}{|c|}{ Nama } & Validator & Skor & Kriteria \\
\hline 1. & $\begin{array}{l}\text { Hendra, } \\
\text { St., Mt. }\end{array}$ & $\begin{array}{c}\text { Ahli } \\
\text { Media }\end{array}$ & $71 \%$ & $\begin{array}{c}\text { Sangat } \\
\text { Baik }\end{array}$ \\
\hline 2. & $\begin{array}{l}\text { Riza } \\
\text { Syamsin } \\
\text { ar, St., } \\
\text { Mt }\end{array}$ & $\begin{array}{c}\text { Ahli } \\
\text { Media }\end{array}$ & $71 \%$ & $\begin{array}{c}\text { Sangat } \\
\text { Baik }\end{array}$ \\
\hline 3. & $\begin{array}{l}\text { Prof. Dr. } \\
\text { Sapardi } \\
\text { Djoko } \\
\text { Damono }\end{array}$ & Ahli & $73 \%$ & $\begin{array}{c}\text { Sangat } \\
\text { Baik }\end{array}$ \\
\hline 4. & $\begin{array}{l}\text { Abidin } \\
\text { Ahmad, } \\
\text { M. Pd. }\end{array}$ & $\begin{array}{l}\text { Ahli } \\
\text { Materi }\end{array}$ & $73 \%$ & $\begin{array}{c}\text { Sangat } \\
\text { Baik }\end{array}$ \\
\hline \\
menunjukan hasil yang sangat \\
digunakan sebagai media pembelajaran. \\
\hline
\end{tabular}

Selanjutnya, revisi produk dihasilkan berdasarkan wawancara, komentar dan saran dari ahli media dan ahli materi. Ahli media dan ahli materi diminta untuk mengisi angket yang telah peneliti berikan. Setelah direvisi, bahan ajar yang telah peneliti buat diuji cobakan ke dua SMP yang berada di daerah Jakarta Selatan. Uji coba dilakukan untuk mengetahui keterbacaan media game sastra sebagai media pembelajaran baru bagi SMP.

Hasil media game sastra sebagai berikut.

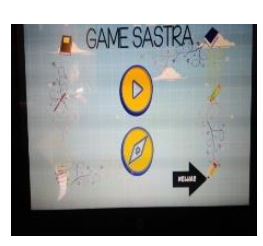

Cover Game

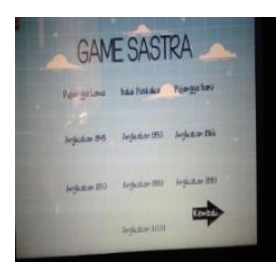

Awal Menu

\section{Gambar 4.2}

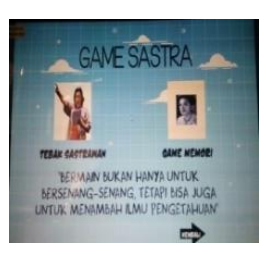

Awal Game

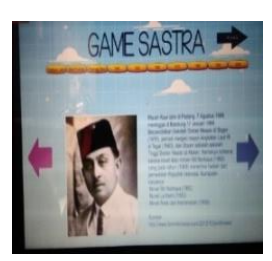

Materi 
Eri Syafitri Hasudungan ${ }^{1)}$,, Wika Soviana Devi ${ }^{2)}$ : Pengembangan Game Sastra (Gasas) untuk Pembelajaran Karya Sastra dari Berbagai Angkatan bagi Siswa SMP

Website : https://jurnal.umj.ac.id/index.php/penaliterasiEmail : penaliterasi@umj.ac.id

* Program atau coding agar game yang

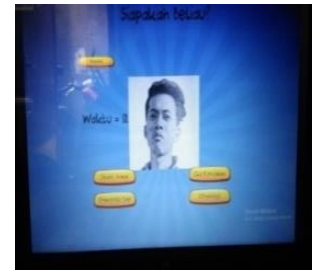

\section{Isi Game}

\section{KESIMPULAN}

Berdasarkan penelitian yang telah dilakukan dapat disimpulkan sebagai berikut.

1. Tingkat kelayakan pengembangan game sastra (gasas) untuk pembelajaran karya sastra dari berbagai angkatan bagi siswa

SMP didapatkan berdasarkan ahli materi dengan presentase 73 kategori "sangat baik" untuk digunakan sebagai media pembelajaran dari presentase tertinggi 75 . Presentase oleh ahli media dengan presentase 71 dengan kategori "sangat baik" untuk digunakan sebagai media pembelajaran dari presentase tertinggi 75 .

2. Tahapan Pengembangan game sastra (gasas).

* Pengembangan game sastra (gasas) menggunakan aplikasi unity 3D.

* Flowchart untuk menentukan letak menu, pembelajaran, dan konsep permainan.

* Desain game berupa gambar, logo game, font game, beckground dan sejenisnya.

* Materi yang akan dimasukan ke dalam game. saya buat dapat berjalan di PC (personal computer).

* Desain dan programnya dengan menggunakan android studio dan unity 3D.

3. Penerapan yang peneliti lakukan dalam pembelajaran pengembangan game sastra dari berbagai angkatan menggunakan media komputer dan melaksanakan di dalam laboratorium komputer. Siswa akan

belajar menggunakan komputer dan peneliti memperhatikan siswa dalam penggunaan kommputer agar tidak menyimpang untuk membuka hal lain selain pembelajaran.

\section{REFERENSI}

Emzir. 2013. Metodologi Penelitian Pendidikan Kuantitaif\&Kualitatif. Depok: PT. Raja Grafindo Persada.

Gall. M.D. Gall. J. D dan Borg W. R. 2003. Educational Research An Introduction 7th Ed. New York: Pecarson Education Inc.

Nurgiyantoro, Burhan. 2010. Penilaian Pembelajaran Bahasa Berbasis Kompetensi. Yogyakarta:BPFE Yogyakarta.

Sugiyono. 2016. Metode Penelitian Kualitatif, Kuantitatif dan $R \& D$. Bandung: Alfabeta. 